\title{
Flu-Like Symptoms
}

National Cancer Institute

\section{Source}

National Cancer Institute. Flu-Like Symptoms. NCI Thesaurus. Code C78302.

Complaints describing a pattern similar to influenza, which may include one or more of the following symptoms: fever, chills, muscle or body aches, cough, sore throat, rhinitis, or fatigue. 